\title{
ORAL NIFEDIPINE VERSUS INTRAVENOUS LABETALOL FOR CONTROL OF BLOOD PRESSURE IN SEVERE PREECLAMPSIA
}

\author{
V. Ratna Kumari ${ }^{1}$, K. Saraswathi², A. Srilaxmi ${ }^{3}$ \\ ${ }_{1}^{1}$ Professor, Department of Obstetrics \& Gynaecology, Niloufer Hospital, Hyderabad. \\ ${ }^{2}$ Associate Professor, Department of Obstetrics \& Gynaecology, Niloufer Hospital, Hyderabad. \\ ${ }^{3}$ Civil Assistant Surgeon, Community Health Centre, Metpally, Karimnagar.
}

\section{ABSTRACT}

\section{OBJECTIVE}

To compare the efficacy of oral nifedipine and IV Labetalol in acute blood pressure control in severe preeclampsia.

\section{METHODS}

200 women with blood pressure $\geq 160 \mathrm{mmHg}$ systolic and/or $\geq 110 \mathrm{mmHg}$ diastolic were randomized to receive oral nifedipine (10 mg tablet orally up to five doses) or IV labetalol in escalating doses of $20 \mathrm{mg}, 40 \mathrm{mg}, 80 \mathrm{mg}, 80 \mathrm{mg}$ and $80 \mathrm{mg}$. They were administered drugs every 15 minutes until blood pressure was less than or equal to $150 \mathrm{~mm} \mathrm{Hg}$ systolic and $100 \mathrm{~mm} \mathrm{Hg}$ diastolic. Crossover treatment was administered if the initial treatment failed. The time required to reduce blood pressure to target value, the number of doses required and the adverse effects were measured. The statistical value of significance was taken at $\mathrm{P}<0.05$.

\section{RESULTS}

The patients who came in the inclusion criteria were treated with either nifedipine or labetalol based on their randomization number. It was found that oral nifedipine required $34.77 \pm 4.8$ minutes whereas Inj. labetalol required $36.61 \pm 5.2$ minutes to control blood pressure. The P value was 0.29.This indicates that the difference was not significant. Oral nifedipine required two doses each of $10 \mathrm{mg}$ to reduce blood pressure whereas Inj. labetalol required 3 doses, a total of $140 \mathrm{mg}$ to reduce blood pressure to the target level. The p-value calculated was 0.43 indicating the difference was not significant. Patients were also monitored for any side effects that may arise from the drugs. The adverse effects noted were dizziness, sweating, flushing, nausea, vomiting, palpitations, headache, shortness of breath and foetal tachycardia. Adverse effects observed were very few and of minor degree. There was no statistical difference in adverse effects noted in both the groups.

\section{CONCLUSIONS}

Oral nifedipine and IV labetalol are similarly effective in the control of severe hypertension in pregnancy.

\section{KEYWORDS}

Preeclampsia Labetalol Nifedipine Hypertension, Pregnancy.

HOW TO CITE THIS ARTICLE: Kumari VR, Saraswathi K, Srilaxmi A. Oral nifedipine versus intravenous labetalol for control of blood pressure in severe preeclampsia. J. Evolution Med. Dent. Sci. 2016;5(20):994-997, DOI: 10.14260/jemds/2016/231

\section{INTRODUCTION}

Hypertensive disorders are one of the most common medical disorders complicating pregnancy and form part of a deadly triad along with haemorrhage and sepsis in contributing greatly to the maternal morbidity and mortality.(1) The incidence of hypertensive disorders ranges from $2-8 \%$ of all pregnancies and contribute to $9 \%$ of maternal mortality in Asia and $12 \%$ in India. $(2,3,4)$ It has been estimated by the WHO that worldwide approximately 45,000 women will die each year from hypertensive disorders of pregnancy. The spectrum of hypertensive diseases that can complicate pregnancy are broad ranging from gestational hypertension, preeclampsia, chronic hypertension and chronic hypertension with superimposed pre-eclampsia. Preeclampsia, a multisystem disorder defined as hypertension of $140 / 90 \mathrm{mmHg}$ or more associated with significant proteinuria $(\geq 30 \mathrm{mg} / \mathrm{dl}$ in random urine samples or $>300 \mathrm{mg} / 24 \mathrm{hrs}$ urine or on dipstick $1+$ or more proteinuria), usually develops after $20 \mathrm{wks}$ of gestation.

Financial or Other, Competing Interest: None.

Submission 26-01-2016, Peer Review 22-02-2016,

Acceptance 26-02-2016, Published 08-03-2016.

Corresponding Author:

K. Saraswathi,

Associate Professor,

Department of Obstetrics \& Gynaecology,

Niloufer Hospital. Hyderabad.

E-mail: saraswathikokkirala@gmail.com

DOI: 10.14260/jemds/2016/231
It is often described as a pregnancy specific syndrome of reduced organ perfusion secondary to vasospasm and endothelial activation. Preeclampsia is a progressive disorder and current therapy doesn't ameliorate the placental pathology or natural history of pre-eclampsia. Delivery is the definitive management and is followed by resolution At mature gestational age delivery should not be delayed but prolongation of pregnancy is desirable at early gestation to improve the foetal prognosis.

Severe preeclampsia is characterized by systolic blood pressure $\geq 160 \mathrm{mmHg}$ and diastolic blood pressure of $\geq 110 \mathrm{mmHg}$. Severe preeclampsia requires prompt treatment to prevent cerebrovascular and cardiovascular complications such as hypertensive encephalopathy, intracerebral haemorrhage and pulmonary oedema.(5,6) It also presents an increased risk of complications for the foetus including prematurity, low birth weight, NICU admissions and eventually foetal death.

Antihypertensive treatment should be started in women with severe hypertension $\geq 160 / 110 \mathrm{mmHg}$ to reduce the blood pressure between $140-155 \mathrm{mmHg}$ systolic and 90 $100 \mathrm{mmHg}$ diastolic. Care should be taken not to lower the blood pressure too rapidly so as to avoid reduced renal and placental perfusion and intrauterine hypoxia leading to sudden foetal death. The most commonly used antihypertensive drugs for control of severe hypertension in pre-eclampsia are nifedipine, labetalol and hydralazine. 
Nifedipine has the advantage of being cost effective, rapid onset of action, long duration of action, oral bioavailability, easier to store and infrequent side effects. Intravenous labetalol is effective in controlling severe hypertension. It can be given when the patient is unconscious but it is not cost effective.

A recent meta-analysis demonstrated that IV hydralazine for the control of severe hypertension in pregnancy was associated with significant maternal hypotension, placental abruption, maternal oliguria and adverse effect on foetal heart rate.(7) They conclude that they do not support the use of hydralazine as the first line treatment. Hydrazine is not available in Indian market. Hence the aim of the present study is to compare the two most commonly used drugs in India, i.e. oral nifedipine and IV labetalol in terms of time taken to lower the blood pressure, dosage required, adverse effects, the maternal and perinatal morbidity and mortality, cost effectiveness and ease of administration.

\section{METHODS}

This prospective randomised controlled trial was conducted in the Department of Obstetrics and Gynaecology Niloufer hospital Hyderabad from October 2012 to November 2014.Institutional ethical committee clearance was obtained before starting this study. A written informed consent was taken from all the study participants.

Pregnant women at $\geq 20$ wks of gestation with sustained severe hypertension $\geq 160 \mathrm{mmHg}$ systolic and $\geq 110 \mathrm{mmHg}$ diastolic blood pressure and significant proteinuria who came to the labour ward or OPD at Niloufer Hospital were included in the trial. Patients with cardiac disease, asthma, nonpregnancy related hypertension, any antihypertensive drug taken $24 \mathrm{hrs}$. prior to enrolment were excluded from the study.

Assignment of the participants was done using computer generated randomized number chart. Patients with even numbers were allotted to nifedipine group and odd numbers were allotted to labetalol group. Once patient was admitted detailed obstetric and medical history, physical examination and obstetric examination findings were entered in the proforma.

Once the basic details were entered, the B.P was recorded again. A sphygmomanometer was used to record blood pressure manually. Blood pressure was checked in the right arm with the cuff covering at least $2 / 3$ rd of the arm. Systolic pressure corresponding to the appearance of the Korotkoff sounds and Diastolic pressure corresponding to the disappearance of Korotkoff $\mathrm{v}$ sounds.

The patients were administered either nifedipine or labetalol based on the randomization. Patients randomized to the labetalol group were administered with $20 \mathrm{mg}(4 \mathrm{ml})$ of labetalol. Blood pressure was measured every 5 minutes. The second dose of $40 \mathrm{mg}(8 \mathrm{ml}$ ) labetalol was given if the target blood pressure of $\leq 150 / 100 \mathrm{mmHg}$ was not achieved within 15 minutes. If blood pressure was not controlled another dose of $80 \mathrm{mg}(16 \mathrm{ml})$ was infused. This was repeated at 15 minute interval for two more times till a maximum dose of $300 \mathrm{mg}$ was administered. If after five cycles of labetalol regimen target blood pressure was not achieved crossover to nifedipine regimen was carried out. Inj. labetalol was infused at a slow rate over 2-5 minutes. The patients belonging to the nifedipine group were given $10 \mathrm{mg}$ of nifedipine capsule as the first dose.
The 10mg dose was repeated every 15 minutes till the target blood pressure was achieved or total 5 doses of nifedipine are given. Nifedipine was never given sublingually. Crossover treatment with labetalol was administered if the nifedipine treatment failed.

The time required for blood pressure to reach the target value was noted. The number of doses required to achieve the target value was noted. Adverse effects like nausea, vomiting, dizziness, palpitations, chest pain, sweating and shortness of breath if any were noted. The mode of delivery, maternal and perinatal morbidity and mortality were noted. The neonates if admitted in NICU were followed up till discharge.

\section{RESULTS}

Regarding the age distribution in the study group the mean age of labetalol group was $23.74 \pm 3.9$ yrs. and $24.36 \pm 3.9$ yrs. in nifedipine group. In labetalol group $45 \%$ belonged to $21-24$ yrs. age group and in the nifedipine group $48 \%$ belonged to the same age group. (Table1).

Gravida distribution shows maximum patients of preeclampsia were primigravida in both the groups (58\% in the labetalol and 50\% in the nifedipine group). Most patients with preeclampsia belonged to 33-36 wks. gestational age (54\% in labetalol and 64\% in nifedipine group). Minimum gestational age at presentation was 26 wks. and 28 wks. in labetalol and nifedipine group respectively. (Table 1).

The systolic blood pressure on the day of admission was $160 \mathrm{mmHg}$ in $34 \%$ of labetalol group and $38 \%$ of nifedipine group, $200 \mathrm{mmHg}$ in $5 \%$ of labetalol and $4 \%$ of nifedipine group. The mean systolic blood pressure on the day of admission was $172.2 \mathrm{mmHg}$ in labetalol group and 170.6 $\mathrm{mmHg}$ in nifedipine group ( $\mathrm{p}$ value 0.87 not significant). The mean diastolic blood pressure on the day of admission was $114.8 \mathrm{mmHg}$ in labetalol group and $115.20 \mathrm{mmHg}$ in nifedipine group ( $\mathrm{p}$ value 0.72 not significant).

The minimum time to achieve target B.P was $10 \mathrm{~min}$. in both the groups. The mean time taken to achieve the target B.P $36.61 \pm 5.2 \mathrm{~min}$ in labetalol group and $34.77 \pm 4.8 \mathrm{~min}$. in nifedipine group ( $\mathrm{p}$ value was 0.29 which was not significant statistically). The target B.P was achieved within 80 min. in both groups. (Table 2).

On an average the labetalol group needed three doses and the nifedipine group required two doses to control the B.P to target level. The $p$ value of 0.43 indicates that there was no significant difference in the number of dose required to achieve the desired B.P.14\% of labetalol group and nifedipine group required crossover treatment. (Table 3 ).

The various side effects of the drugs like dizziness, sweating, nausea, vomiting, palpitations, headache and shortness of breath showed no statistical significance among the two drugs. Maternal hypotension or foetal tachycardia were not seen in either of the study groups. (Table 4). Regarding mode of delivery in nifedipine group there were 52 caesarean sections and 48 vaginal deliveries. In labetalol group there were 44 caesarean sections and 56 vaginal deliveries. $\mathrm{p}$ value 0.25 did not reveal any statistical significance.

The average birth weight of babies in nifedipine group was $2.31 \mathrm{~kg}$ and for the labetalol group was $2.28 \mathrm{~kg}$. p value was 0.72 which was not statistically significant. (Table 5). The Apgar score of $<7$ at 5 mins. was seen in $14 \%$ of the labetalol group and $12 \%$ of the nifedipine group. 
$86 \%$ of the labetalol group and $88 \%$ of the nifedipine group showed Apgar score of $\geq 7$ at 5 mins. $p$ value of 0.67 was not significant statistically. The neonatal complications like prematurity, NICU admissions, respiratory distress and hyperbilirubinemia were comparable among the two groups There were 3 IUD's and 8 neonatal deaths among the labetalol group and 2 IUD's and 10 neonatal deaths in the nifedipine group. The $p$ value was not statistically significant. (Table 6).

\section{DISCUSSION}

This randomized controlled study compares the efficacy of two antihypertensive drugs, oral nifedipine and I. V. Labetalol. 200 patients were included in the trial of which 100 were randomized to nifedipine and another 100 were randomised to labetalol group.

All the patients were aged between 18-40yrs. Mean age in the labetalol group was $23.74 \pm 3.9$ and $24.36 \pm 3.9$ in the nifedipine group comparable to the study conducted by Dhali B et al.(8) With regard to gravida distribution maximum patients of pre-eclampsia were primigravida in both the groups, $58 \%$ in the labetalol and $50 \%$ in nifedipine group comparable with the study of Shekar et al 2013.(9) and Raheem et al.(10)

In the present study most patients with preeclampsia were between $33-36 w k$ s of gestation, $54 \%$ in labetalol and $64 \%$ in nifedipine group. Mean gestational age in labetalol group is $35.4 \pm 2.12 \mathrm{wks}$ and in nifedipine group $35.3 \pm 2.3 \mathrm{wks}$. In a study conducted by Sekhar et al mean gestational age was $36.1 \pm 3.2 \mathrm{wks}$ in labetalol group and $37.3 \pm 2.12 \mathrm{wks}$ in nifedipine group.

In our study the mean systolic blood pressure in labetalol group was $172.2 \pm 8.6 \mathrm{mmHg}$ and in nifedipine group it was $170.6 \pm 6.4 \mathrm{mmHg}$. $p$ value was 0.87 which is not significant. In the study conducted by Raheem et al the systolic blood pressure was $170 \mathrm{mmHg}$ in labetalol group and $175 \mathrm{mmHg}$ in nifedipine group. In the present study the mean diastolic blood pressure in labetalol group was $115.2 \pm 2.6 \mathrm{mmHg}$ and in nifedipine group it was $114.8 \pm 2.5$. $p$ value was 0.7 which is not significant. In the study of Raheem et al the mean diastolic blood pressure was $108 \mathrm{mmHg}$ in labetalol group and 110 $\mathrm{mmHg}$ in nifedipine group.

In the present study the mean time taken to achieve target blood pressure in labetalol group is $36.61 \pm 5.2$ minutes and in nifedipine group it is $34.77 \pm 4.8$ minutes. $p$ value was 0.29 which is not statistically significant. Many studies have shown that both labetalol and nifedipine can be used successfully in treating hypertensive crisis in pregnancy. In the study conducted by Raheem et al on the same drugs in pregnancy the median time taken by the labetalol group to achieve target blood pressure was 45 minutes and by the nifedipine group was 30 minutes which is comparable to our study.

The Trial conducted by Vermillion et al.(11) indicated that patients receiving oral Nifedipine more rapidly achieved therapeutic blood pressure goal in $25.0 \pm 13.6$ minutes as compared with $43.6 \pm 25.4$ minutes in women receiving intravenous labetalol $(\mathrm{P}=0.002)$. Vermillion drug regimen used higher oral nifedipine doses i.e. $10 \mathrm{mg}$ initially, then $20 \mathrm{mg}$ for further doses as required. We used $10 \mathrm{mg}$ nifedipine throughout. Intravenous labetalol dose used was $20,40,80,80$ and $80 \mathrm{mg}$ in their study which is identical to the dose of labetalol used in our study.

In our study nifedipine group required 2 doses to reduce the blood pressure and labetalol group required 3 doses to achieve the same effect keeping with the findings of Raheem et al. In our study $14 \%$ of labetalol group and $14 \%$ of nifedipine group required crossover treatment with nifedipine and labetalol respectively. In the study conducted by Raheem et al $20 \%$ of labetalol group and $20 \%$ of nifedipine group required crossover treatment.

Regarding the side effects of the two drugs there was no incidence of maternal hypotension or foetal tachycardia in both the groups. Other side effects were of minor degree and are comparable with other studies. In our study the mean birth weight was $2.28 \pm 0.5$ in labetalol group and $2.31 \pm 0.24$ in nifedipine group which is comparable with the study of Shekar et al (2013) where the mean birth weight in labetalol group was $2.2 \pm 0.60 \mathrm{~kg}$ and $2.4 \pm 0.50 \mathrm{~kg}$ in nifedipine group.

Regarding neonatal complications the more number of admissions and respiratory distress when compared to other studies done on the same drugs are due to more number of preterm deliveries in the present study.

Cochrane review of 2006 has concluded that there is no clear evidence that one antihypertensive is preferable to the other for improving outcome for women with very high blood pressure during pregnancy. Until better evidence is available the best choice of drug for an individual woman probably depends on the experience and familiarity with a particular drug and its maternal and foetal side effects.(12)

Our study indicates that both oral nifedipine and intravenous labetalol regimens are effective in controlling severe hypertension in pregnancy. There were no major side effects attributable to either drug regimens. Our study is in accordance with the guidelines and expert opinion that oral nifedipine and intravenous labetalol can be used as first line antihypertensive drugs for control of severe hypertension in pregnancy. $(13,14)$.

\section{CONCLUSION}

In the present study, both oral nifedipine and IV labetalol were equally effective in the control of hypertension in severe preeclampsia. Both drugs demonstrated a similar adverse effects profile.

Nifedipine is easier to store, easier to administer as it is given orally whereas IV labetalol is more expensive, needs to be stored at a lower temperature and needs slower administration.

Thus the present study concludes that both oral nifedipine and IV labetalol are equally effective in acute control of blood pressure in severe pre-eclampsia. Nifedipine can be used in peripheral centres due to its cost effectiveness and its ease of administration and storage. Inj. labetalol can be used in an unconscious or drowsy patient. 


\begin{tabular}{|c|c|c|}
\hline Age of Patients & $\begin{array}{c}\text { LABETALOL } \\
\mathbf{N = 1 0 0}\end{array}$ & $\begin{array}{c}\text { NIFEDIPINE } \\
\mathbf{N = 1 0 0}\end{array}$ \\
\hline 18- 20 YEARS & $26 \%$ & $20 \%$ \\
\hline $21-25$ YEARS & $45 \%$ & $48 \%$ \\
\hline 26- 30 YEARS & $21 \%$ & $19 \%$ \\
\hline $30-40$ YEARS & $8 \%$ & $11 \%$ \\
\hline P value & \multicolumn{2}{|c|}{$0.42 \mathrm{NS}$} \\
\hline \multicolumn{3}{|c|}{ Parity of patients } \\
\hline Primi & 58 & 50 \\
\hline G2 & 24 & 30 \\
\hline G3 & 10 & 16 \\
\hline G4 & 8 & 4 \\
\hline \multicolumn{3}{|c|}{ GESTATIONAL AGE in weeks } \\
\hline $26-28$ & $2 \%$ & $1 \%$ \\
\hline $29-32$ & 24\% & $18 \%$ \\
\hline $33-36$ & Table 1: Distribution of Patients According \\
to Age, Parity and Gestational Age \\
\hline \multicolumn{2}{|c|}{$54 \%$} \\
\hline
\end{tabular}

\begin{tabular}{|c|c|c|c|}
\hline & $\begin{array}{c}\text { LABETALOL } \\
\mathbf{N}=\mathbf{1 0 0}\end{array}$ & $\begin{array}{c}\text { NIFEDIPINE } \\
\mathbf{N = 1 0 0}\end{array}$ & $\begin{array}{c}\text { P } \\
\text { VALUE }\end{array}$ \\
\hline $\begin{array}{c}\text { MEAN SYSTOLIC } \\
\text { BP (mm Hg) }\end{array}$ & 172.2 & 170.6 & 0.89 \\
\hline $\begin{array}{c}\text { MEAN } \\
\text { DIASTOLIC BP } \\
\text { (mm Hg) }\end{array}$ & 114.8 & 115.20 & 0.72 \\
\hline $\begin{array}{c}\text { MEAN TIME } \\
\text { TAKEN TO } \\
\text { CONTROL BP }\end{array}$ & $\begin{array}{c}36.31 \pm 5.2 \\
\text { MINUTES }\end{array}$ & $\begin{array}{c}34.77 \pm 4.8 \\
\text { MINUTES }\end{array}$ & 0.29 \\
\hline $\begin{array}{c}\text { Table 2: Comparison between Systolic and Diastolic BP on day of } \\
\text { Admission and Time Taken to Control BP }\end{array}$ \\
\hline
\end{tabular}

\begin{tabular}{|c|c|c|}
\hline $\begin{array}{c}\text { NUMBER OF } \\
\text { DOSES }\end{array}$ & $\begin{array}{c}\text { LABETALOL } \\
\mathbf{N = 1 0 0}\end{array}$ & $\begin{array}{c}\text { NIFEDIPINE } \\
\mathbf{N = 1 0 0}\end{array}$ \\
\hline 1 & $19 \%$ & $26 \%$ \\
\hline 2 & $28 \%$ & $29 \%$ \\
\hline 3 & $29 \%$ & $16 \%$ \\
\hline 4 & $10 \%$ & $8 \%$ \\
\hline 5 & $10 \%$ & $7 \%$ \\
\hline CROSS OVER & $14 \%$ & $14 \%$ \\
\hline TREATMENT & Table 3: Number of Doses of \\
Drugs Required to Control BP \\
\hline
\end{tabular}

\begin{tabular}{|c|c|c|c|}
\hline $\begin{array}{c}\text { ADVERSE } \\
\text { EFFECT }\end{array}$ & $\begin{array}{c}\text { LABETALOL } \\
\mathbf{N}=\mathbf{1 0 0}\end{array}$ & $\begin{array}{c}\text { NIFEDIPINE } \\
\mathbf{N = 1 0 0}\end{array}$ & $\begin{array}{c}\text { P } \\
\text { VALUE }\end{array}$ \\
\hline HYPOTENSION & 0 & 0 & \\
\hline DIZZINESS & $4 \%$ & $6 \%$ & 0.15 \\
\hline FLUSHING/ SWEATING & $2 \%$ & $1 \%$ & 0.56 \\
\hline NUUSEA/VOMITING & $4 \%$ & $8 \%$ & 0.23 \\
\hline PALPITATION & $6 \%$ & $10 \%$ & 0.29 \\
\hline HEADACHE & $8 \%$ & $12 \%$ & 0.34 \\
\hline $\begin{array}{c}\text { SHORTNESS OF } \\
\text { BREATH }\end{array}$ & $4 \%$ & $4 \%$ & $1 \%$ \\
\hline FETAL TACHYCARDIA & 0 & 0 & \\
\hline \multicolumn{4}{|c|}{ Table 4: Adverse Effects of the Drugs in the Study Group } \\
\hline
\end{tabular}

\begin{tabular}{|c|c|c|}
\hline $\begin{array}{c}\text { BIRTH } \\
\text { WEIGHT }\end{array}$ & $\begin{array}{c}\text { LABETALOL } \\
\mathbf{N = 1 0 0}\end{array}$ & $\begin{array}{c}\text { NIFEDIPINE } \\
\mathbf{N = 1 0 0}\end{array}$ \\
\hline$<1.5 \mathrm{KG}$ & 10 & 10 \\
\hline $1.6-2.5$ & 52 & 50 \\
\hline $2.6-3.5$ & 37 & 38 \\
\hline$>3.5$ & 1 & 2 \\
\hline \multicolumn{3}{|c|}{ Table 5: Birth weight in $\mathbf{K g}$} \\
\hline
\end{tabular}

\begin{tabular}{|c|c|c|c|}
\hline $\begin{array}{c}\text { NEONATAL } \\
\text { COMPLICATIONS }\end{array}$ & $\begin{array}{c}\text { LABETALOL } \\
\mathbf{N = 1 0 0}\end{array}$ & $\begin{array}{c}\text { NIFEDIPINE } \\
\mathbf{N = 1 0 0}\end{array}$ & $\begin{array}{c}\text { P } \\
\text { VALUE }\end{array}$ \\
\hline PRETERM & 30 & 31 & 0.88 \\
\hline NICU ADMISSION & 23 & 20 & 0.60 \\
\hline RDS & 15 & 17 & 0.69 \\
\hline
\end{tabular}

\begin{tabular}{|c|c|c|c|}
\hline $\begin{array}{c}\text { HYPER } \\
\text { BILIRUBINEMIA }\end{array}$ & 20 & 25 & 0.39 \\
\hline IUGR & 24 & 20 & 0.49 \\
\hline IUD & 3 & 2 & 0.65 \\
\hline $\begin{array}{c}\text { NEONATAL } \\
\text { MORTALITY }\end{array}$ & 8 & 10 & 0.62 \\
\hline \multicolumn{2}{|c|}{ Table 6: Neonatal Complications } \\
\hline
\end{tabular}

\section{REFERENCES}

1. Cunningham FG, Leveno KJ, Bloom SL, et al. Hypertensive disorders of pregnancy. Chapter in Cunningham, F Gary. III. Williams, Jeds, Williams Obstetrics, 23rd edition;34:706709.

2. Khan KS, Daniel W, Say L, et al. WHO analysis of causes of maternal death: a systematic review. Lancet 2006;367:1066-74.

3. Kausar R. Maternal mortality in India: magnitude, causes and concerns. Indmedica 2005-06;2(2).

4. Roberts JM, Pearson G, Cutler J, et al. Summary of the NHLBI working group on research on hypertension during pregnancy. Hypertension 2003;41(3):437-45.

5. National Institute of Health and Clinical Excellence. Hypertension in pregnancy: the management of hypertensive disorders during pregnancy. NICE clinical guidelines 107. [Online] 2010. Available from www.nice.org.uk/niemedia/live/13098/50418 Pdf

6. Berg CJ, Chang J, Callaghan WM, et al. Pregnancy-related mortality in the united states 1991-1998. Obstet Gynecol 2003;101(2):289-96.

7. Magee, Cham C, Waterman EJ, et al. Hydralazine for treatment of severe hypertension in pregnancy: metaanalysis. BMJ 2003;327(7421):955-60.

8. Dhali B, Bhattacharya S, Ganguly RP, et al. A randomized trial of intravenous labetolol and oral nifedipine in severe pregnancy induced hypertension. Int J Reprod Contracept Obstet Gynecol 2012;1:42-6.

9. Shashank Shekhar, Chanderdeep Sharma, Sita Thakur, et al. Oral nifedipine or intravenous labetolol for hypertensive emergency in pregnancy; a randomized trial. Obstet Gynecol 2013;122(5):1057-63.

10. Raheem I, Saaid R, mar S, et al. Oral nifedipine versus intravenous labetalol for acute blood pressure control in hypertensive emergencies of pregnancy; a randamized trial. BJOG 2012;119:78-85.

11. Vermillion ST, Scardo JA, Newman RB, et al. A randomized, double-blind trial of oral nifedipine and intravenous labetalol in hypertensive emergencies of pregnancy. Am J Obstet Gynecol 1999;181:858-61.

12. Duely L, Henderson-Smart DJ, Meher S. Drugs for treatment of very high blood pressure during pregnancy. Cochrane Database Syst Rev 2006;47:279-85.

13. The Royal College of Obstetricians and Gynaecologists, United kingdom. Green top guideline No 10(A). The management of severe pre-eclampsia/eclampsia. 2006. Accessible online www.rcog.org.uk/files/GT10a ManagementPreeclampsia2006.pdf.

14. Sibai BM. Diagnosis and mangement of gestational hypertension and preeclampsia. Obstet Gynaecol 2003;102:181-92. 